\title{
Effect of continuous slow-speed running for 12 weeks on 10-14-year-old Indian boys
}

\author{
Satipati Chatterjee MSc PhD and Anupam Bandyopadhyay \\ Exercise, Sports and Cardiorespiratory Physiology Laboratory, Department of Physiology, University Colleges \\ of Science and Technology, Calcutta, India
}

\begin{abstract}
Endurance training was conducted on a group of 41 East Indian boys aged 10-14 years and was compared with 25 untrained boys of the same age. A continuous slowrunning method was adopted for 12 weeks. The intensity of the training was $\mathbf{8 0}-\mathbf{8 5} \%$ of maximum heart rate and frequency was 3 days per week. The boys were trained for a 1500-m event and therefore they covered three to five times their racing distance. For psychological reasons the training was carried out in a playground. The investigations included different physical and motor fitness tests: measurement of flexibility, agility, speed, leg muscle strength etc. Their performance times were also recorded before and after training. From statistical analysis we concluded that this particular type of training programme did not produce any detrimental effects on 10-14-year-old boys. On the other hand, this type of training did have some influence on improving physiological parameters in this age group of boys when compared with untrained boys of the same age.
\end{abstract}

Keywords: Endurance training, continuous slow running, physiological development, motor development, 1500-m event

The potential detrimental effects of distance running on children have recently been called to the attention of sports and exercise physiologists. The Medical Committee of the International Athletics Association Federation $(1983)^{1}$ recommended that training and competition for long-distance track and road-running events should not be encouraged in children. Another statement by the American Academy of Pediatrics $(1982)^{2}$ lists the potential dangers of distance running, but it does not recommend specific age-distance relationships.

A review of the scientific literature provides little evidence that long-distance running is detrimental to children's growth ${ }^{3-5}$. Conversely, neither does it give any reassurance that these intensive training regimens are harmless for growth ${ }^{6,7}$. Investigators have also been unable to define the level or intensity of training in children at which the beneficial effects

Address for correspondence: Dr Satipati Chatterjee, Department of Physiology, University Colleges of Science and Technology, 92, Acharya Prafulla Chandra Road, Calcutta 700009, India

(C) 1993 Butterworth-Heinemann Ltd

0306-3674/93/030179-07 cease and injuries, which are the first indications of potential growth impairment, begin to accumulate.

In India, children take part in many different training programmes. As endurance training is easy to adopt and has an influence in developing different physiological parameters, most of our coaches and instructors adopt endurance training as a basic training programme. But a problem associated with this type of training is that if intensity, duration and frequency are not properly controlled there may be some risk of injuries to the children.

In earlier studies, different authors investigated the effect of endurance training in general on young athletes, but there are few investigations regarding specific types of endurance training, such as the continuous slow-running method on 10-14-year-old schoolboys. Although the $1500-\mathrm{m}$ event for this age group is still controversial, the purpose of this investigation is to explore the effects of continuous slow running for 12 weeks on this age group. Therefore, our studies are restricted to finding out if this type of training produces any beneficial or detrimental effects on 10-14-year-old inexperienced runners.

\section{Subjects and method}

The investigations were conducted on boys of 10-14 years of age. The subjects were from a school in North Bengal. The boys were taken randomly from the school, and 41 of the 10-14-year-old boys were interested in participating in this training programme. A control group was formed from 25 subjects of the same age group and they did not take part in this training programme, but were engaged in their daily sports and games. The dates of birth of the boys were recorded from the school register.

\section{Training method}

The experimental group consisted of 41 boys of 10-14 years of age and were trained for 3 days per week for about $30 \mathrm{~min}$ for 12 weeks. The intensity of the training was $80-85 \%$ of their maximum heart rate and the pace was about $8 \mathrm{~min} / \mathrm{mile}^{8}$. Training always began with a few minutes' warm-up and was followed by outdoor continuous slow running. The boys were in training for a 1500-m event and 
Table 1. The mean values of performance of experimental and control groups in different tests before the training programme

\begin{tabular}{|c|c|c|c|c|c|}
\hline \multirow[b]{2}{*}{ Parameter } & \multicolumn{5}{|c|}{ Age group (category) } \\
\hline & $\begin{array}{c}10 \text { years } \\
E G, n=9 \\
C G, n=5\end{array}$ & $\begin{array}{c}11 \text { years } \\
E G, n=9 \\
C G, n=5\end{array}$ & $\begin{array}{c}12 \text { years } \\
E G, n=9 \\
C G, n=5\end{array}$ & $\begin{array}{c}13 \text { years } \\
E G, n=8 \\
C G, n=5\end{array}$ & $\begin{array}{c}14 \text { years } \\
E G, n=6 \\
C G, n=5\end{array}$ \\
\hline \multicolumn{6}{|l|}{ Height (m) } \\
\hline EG & $1.31(0.04)$ & $1.36(0.04)$ & $1.44(0.07)$ & $1.46(0.08)$ & $1.51(0.07)$ \\
\hline CG & $1.29(0.01)$ & $1.34(0.03)$ & $1.45(0.05)$ & $1.46(0.09)$ & $1.51(0.06)$ \\
\hline \multicolumn{6}{|l|}{ Weight (kg) } \\
\hline EG & $25.05(2.21)$ & $27.83(3.52)$ & $30.67(5.71)$ & $36.5(5.28)$ & $37.17(6.67)$ \\
\hline CG & $24.6(0.82)$ & $26.9(0.82)$ & $30.7(3.42)$ & $36.2(2.19)$ & $36.9(4.29)$ \\
\hline \multicolumn{6}{|c|}{ Resting heart rate (beats/min) } \\
\hline EG & $88(8.51)$ & 88(13.29) & $88(9.05)$ & $85(14.93)$ & 84(11.41) \\
\hline CG & $86(2.00)$ & $88(1.41)$ & $87(2.28)$ & $85(2.68)$ & $84(2.61)$ \\
\hline \multicolumn{6}{|c|}{ Maximum heart rate (beats/min) } \\
\hline EG & $204(7.00)$ & 204(8.06) & $200(8.15)$ & $200(4.69)$ & 192(7.20) \\
\hline CG & 208(6.78) & 204(4.09) & $200(3.74)$ & 199(2.68) & $197(2.28)$ \\
\hline \multicolumn{6}{|c|}{ Systolic blood pressure $(\mathrm{mmHg})$} \\
\hline EG & $85(7.69)$ & $92(9.53)$ & 93(10.87) & $100(8.60)$ & $110(10.98)$ \\
\hline CG & $90(5.55)$ & $91(3.63)$ & $91(3.03)$ & $100(1.41)$ & $111(3.03)$ \\
\hline \multicolumn{6}{|c|}{ Diastolic blood pressure (mmHg) } \\
\hline EG & $56(4.74)$ & $62(4.59)$ & $60(5.83)$ & $64(6.06)$ & $71(3.01)$ \\
\hline CG & $58(2.61)$ & $61(1.79)$ & $60(2.0)$ & $62(2.61)$ & $71(3.03)$ \\
\hline \multicolumn{6}{|c|}{ Flexibility $(\mathrm{cm})$} \\
\hline EG & 44.03(2.98) & 43.74(4.36) & $41.77(3.73)$ & $45.88(3.21)$ & $48.47(5.59)$ \\
\hline CG & $44.19(3.74)$ & $43.95(2.31)$ & $41.93(1.59)$ & $45.21(1.45)$ & $48.01(2.60)$ \\
\hline \multicolumn{6}{|l|}{ Agility (s) } \\
\hline EG & $10.21(2.25)^{*}$ & $12.05(0.84)$ & $11.72(0.67)$ & $11.27(0.73)$ & $11.08(0.86)$ \\
\hline CG & $12.7(0.03)$ & $12.3(0.76)$ & $11.84(0.63)$ & $10.98(0.38)$ & $10.9(0.42)$ \\
\hline \multicolumn{6}{|l|}{ Speed (s) } \\
\hline EG & $10.02(0.58)$ & $9.38(1.07)$ & $9.09(0.58)$ & $8.82(0.63)$ & $8.73(1.23)$ \\
\hline CG & $9.76(0.76)$ & $9.92(1.41)$ & $9.76(1.91)$ & $8.78(0.13)$ & $8.78(0.18)$ \\
\hline \multicolumn{6}{|c|}{ Leg strength (m) } \\
\hline EG & $1.25(0.23)$ & $1.37(0.18)$ & $1.44(0.21)$ & $1.71(0.14)$ & $1.82(0.23)$ \\
\hline CG & $1.29(0.08)$ & $1.36(0.13)$ & $1.44(0.07)$ & $1.69(0.05)$ & $1.76(0.11)$ \\
\hline \multicolumn{6}{|c|}{ Cardiovascular endurancet $(\mathbf{m})$} \\
\hline EG & 1996(149.19) & $2146(162.03)$ & $2179(227.03)$ & $2365(176.72)$ & $2367(277.77)$ \\
\hline CG & $2027(25.12)$ & $2065(54.54)$ & $2145(130.67)$ & $2266(150.93)$ & $2348(136.27)$ \\
\hline \multicolumn{6}{|c|}{ Physical fitness index } \\
\hline & $85.81(12.41)$ & $95.62(18.64)$ & $85.99(12.26)$ & $84.27(16.80)$ & $85.41(8.68)$ \\
\hline CG & $93.06(5.52)$ & $93.6(2.54)$ & $85.22(4.62)$ & $83.66(2.68)$ & $90.55(8.33)$ \\
\hline \multicolumn{6}{|c|}{ Performance time ( $\mathrm{min}$ ) } \\
\hline EG & $8.27(0.21)$ & $8.1(0.12)$ & $7.5(0.27)$ & $7.35(0.08)$ & $7.2(0.13)$ \\
\hline CG & $8.24(0.12)$ & $8.04(0.11)$ & $7.52(0.31)$ & $7.32(0.34)$ & $7.14(0.22)$ \\
\hline
\end{tabular}

Values are mean(s.d.). EG, experimental group; $C G$, control group; $n$, sample size.

${ }^{*} P<0.05$; analysis of variance. +9 -min run for boys under 12 years and 12 -min run for boys over 12 years

therefore they covered three times the distance of their event $(4500 \mathrm{~m})$ in the first 4 weeks, then four times the distance $(6000 \mathrm{~m})$ in the second 4 weeks and five times $(7500 \mathrm{~m})$ in the last 4 weeks of the training programme. In this way the load was increased over the 3 months.

\section{Factors measured}

The following tests were conducted on the subjects before and after the training programme. In the case of the control group, tests were conducted in the same manner both at the beginning of the training programme and after 12 weeks. Different physiological parameters, e.g. height, weight and normal heart rate were measured by conventional methods. Maximum heart rates were measured individually by counting 20 beats immediately after their maximum running distance before and after 12 weeks of the training programme. Systolic and diastolic blood pressure were measured before and after the training programme by allowing the subjects to rest completely for $30 \mathrm{~min}$ in a sitting position. But some other tests were also carried out to make this programme more reliable and more informative. They were as follows.

\section{Physical fitness parameters}

Measurement of flexibility by sit-and-reach test, physical fitness test by Harvard step test, cardiovascular endurance by 9 -min (up to 12 years) and 12-min (13-14 years) run-walk test.

\section{Motor fitness parameters}

Measurement of speed by 50 -yard dash, agility by shuttle run and measurement of leg strength by standing broad jump. Moreover, performance times taken to complete the $1500-\mathrm{m}$ event were also recorded individually before and after training. 


\section{Statistics}

Conventional statistical methods were used to determine mean and standard deviation (s.d.). Analyses of variance were used to determine whether there were any significant differences between the experimental and control groups.

\section{Results and discussion}

Tables 1 and 2 show the mean values of performance and levels of significance of the experimental group and control group in different tests and after the training programme respectively.

\section{Height and weight}

The experimental group and control group did not show any significant change in standing height after
12 weeks of the training programme (Tables 3 and 4). A significant change in weight was found in 10-13-year-olds in the experimental group (Table 3), whereas subjects in the control group did not show any significant change after 12 weeks. As the training period was 12 weeks and the different parameters involved in the measurement of growth were not studied in our investigations, we cannot therefore clearly confirm that this type of training programme influences the growth of the 10-14-year-old age group.

\section{Normal and maximum heart rates}

Normal heart rate was found to be significantly reduced in 10-, 12- and 13-year-old boys in the experimental group (Table 3) and 13-14-year-old boys in the control group (Table 4). But the percentage of

Table 2. The mean values of performance of the experimental and control groups in different tests after the training programme

\begin{tabular}{|c|c|c|c|c|c|}
\hline \multirow[b]{2}{*}{ Variable } & \multicolumn{5}{|c|}{ Age group (category) } \\
\hline & $\begin{array}{c}10 \text { years } \\
E G, n=9 \\
C G, n=5\end{array}$ & $\begin{array}{c}11 \text { years } \\
E G, n=9 \\
C G, n=5\end{array}$ & $\begin{array}{c}12 \text { years } \\
E G, n=9 \\
C G, n=5\end{array}$ & $\begin{array}{c}13 \text { years } \\
E G, n=8 \\
C G, n=5\end{array}$ & $\begin{array}{c}14 \text { years } \\
E G, n=6 \\
C G, n=5\end{array}$ \\
\hline \multicolumn{6}{|c|}{ Height (m) } \\
\hline EG & 1.32.0.04) & $1.37(0.04)$ & $1.46(0.07)$ & $1.48(0.08)$ & $1.53(0.06)$ \\
\hline CG & $1.30(0.01)$ & $1.35(0.03)$ & $1.46(0.05)$ & $1.46(0.09)$ & $1.51(0.07)$ \\
\hline \multicolumn{6}{|c|}{ Weight (kg) } \\
\hline EG & 26.11(1.93) & $30.05(3.50)$ & $32.94(6.13)$ & $37.69(5.15)$ & 38.75(6.38) \\
\hline CG & $24.9(0.82)$ & $27.0(0.93)$ & $31.2(3.59)$ & $36.9(2.46)$ & $37.2(4.51)$ \\
\hline \multicolumn{6}{|c|}{ Resting heart rate (beats/min) } \\
\hline EG & $78(6.35)^{*}$ & $75(4.67)+$ & $77(8.66) \ddagger$ & $69(9.94) \S$ & $70(4.72) \dagger$ \\
\hline CG & $85(1.79)$ & $86(2.19)$ & $84(1.67)$ & $82(2.45)$ & $81(3.03)$ \\
\hline \multicolumn{6}{|c|}{ Maximum heart rate (beats/min) } \\
\hline EG & $192(6.22)^{* *}$ & $191(6.01) \dagger$ & 189(9.08)‡ & $185(7.07)^{* *}$ & 182(4.96) $\dagger$ \\
\hline CG & 205(4.82) & $204(3.74)$ & 198(4.38) & $196(2.19)$ & 194(2.61) \\
\hline \multicolumn{6}{|c|}{ Systolic blood pressure $(\mathrm{mmHg})$} \\
\hline EG & $81(7.53)$ & 84(4.41)‡ & $85(5.09)$ & $91(7.63) \dagger$ & $87(4.50) \dagger$ \\
\hline CG & $87(4.15)$ & $89(3.63)$ & $88(2.83)$ & $98(0.89)$ & $110(2.61)$ \\
\hline \multicolumn{6}{|c|}{ Diastolic blood pressure $(\mathrm{mmHg})$} \\
\hline EG & $53(4.09)^{*}$ & $61(4.37)$ & $56(4.05)$ & $61(3.01)$ & $60(2.04) t$ \\
\hline CG & $58(2.19)$ & $61(1.79)$ & $59(1.09)$ & $61(1.79)$ & $70(1.41)$ \\
\hline \multicolumn{6}{|c|}{ Flexibility $(\mathrm{cm})$} \\
\hline EG & 44.45(4.31) & $45.15(3.65)$ & $44.17(5.38)$ & $46.35(3.11)$ & $48.68(5.72)$ \\
\hline CG & $44.45(3.24)$ & $44.19(2.60)$ & $42.67(1.93)$ & $45.47(1.06)$ & 47.75(2.92) \\
\hline \multicolumn{6}{|c|}{ Agility (s) } \\
\hline EG & $12.19(0.79)$ & $10.77(0.68)^{* *}$ & 11.12(0.52)‡ & 11(0.59) & $10.75(0.62)$ \\
\hline CG & $12.62(0.36)$ & $12.5(0.79)$ & $11.7(0.58)$ & $10.92(0.31)$ & $10.6(0.42)$ \\
\hline \multicolumn{6}{|c|}{ Speed (s) } \\
\hline EG & $9.38(0.38)$ & $8.48(0.51) \S$ & $8.34(0.38) \ddagger$ & $8.30(0.25)^{* *}$ & $7.8(0.37)+$ \\
\hline CG & $9.72(0.81)$ & $9.68(1.09)$ & $9.44(1.79)$ & $8.72(0.13)$ & $8.66(0.17)$ \\
\hline \multicolumn{6}{|c|}{ Leg strength (m) } \\
\hline EG & $1.36(0.13)$ & $1.44(0.23)$ & $1.48(0.24)$ & $1.72(0.14)$ & $1.87(0.22)$ \\
\hline CG & $1.29(0.07)$ & $1.38(0.14)$ & $1.45(0.07)$ & $1.69(0.05)$ & $1.78(0.12)$ \\
\hline \multicolumn{6}{|c|}{ Cardiovascular endurancett (m) } \\
\hline EG & $2290(182.81) \S$ & $2660(216.09) \dagger$ & $2742(187.88) \dagger$ & $2750(147.23)^{* *}$ & $2769(287.82)^{*}$ \\
\hline CG & $2036(27.70)$ & 2170(104.89) & $2255(151.16)$ & $2396(175.87)$ & 2414(172.28) \\
\hline \multicolumn{6}{|c|}{ Physical fitness index } \\
\hline EG & 98.66(16.71) & $107.64(8.17)^{* *}$ & 101.88(16.32)‡ & 105.42(16.14)* & $100.68(9.82)^{*}$ \\
\hline CG & $93.67(5.45)$ & $95.35(2.09)$ & $87.35(5.36)$ & $86.22(2.91)$ & $92.29(7.84)$ \\
\hline \multicolumn{6}{|c|}{ Performance times (min) } \\
\hline EG & $7.9(0.14)^{* *}$ & $7.5(0.26)^{* *}$ & $6.12(0.21) \dagger$ & $5.9(0.33) \dagger$ & $5.87(0.35) \dagger$ \\
\hline CG & $8.13(0.12)$ & $7.96(0.09)$ & $7.48(0.31)$ & $7.18(0.22)$ & $7.04(0.15)$ \\
\hline
\end{tabular}

Values are mean(s.d.). $P$, level of significance; n.s., mean difference is not significant; EG, experimental group; CG, control group; $n$, sample size

${ }^{*} P<0.05 ;+P<0.001 ; \ddagger P<0.10 ; \S P<0.02 ;{ }^{* *} P<0.01$; analysis of variance; $t+9-m i n$ run for boys under 12 years and $12-$ min run for boys over 12 years 
Table 3. Differences in experimental group before and after 12 weeks of the training programme on selected physical and physiological variables

\begin{tabular}{|c|c|c|c|c|c|}
\hline \multirow[b]{2}{*}{ Variable } & \multicolumn{5}{|c|}{ Age group } \\
\hline & $\begin{array}{c}10 \text { years } \\
E G, n=9\end{array}$ & $\begin{array}{c}11 \text { years } \\
E G, n=9\end{array}$ & $\begin{array}{c}12 \text { years } \\
E G, n=9\end{array}$ & $\begin{array}{c}13 \text { years } \\
E G, n=8\end{array}$ & $\begin{array}{c}14 \text { years } \\
E G, n=6\end{array}$ \\
\hline \multicolumn{6}{|l|}{ Height (m) } \\
\hline$F$ values & 0 & 0 & 0 & 0 & 0 \\
\hline \multicolumn{6}{|l|}{ Weight (kg) } \\
\hline$F$ values & $17.31^{*}$ & 88.88* & $49.68^{*}$ & $12.26^{*}$ & 8.64 \\
\hline \multicolumn{6}{|l|}{ Resting heart rate (beats/min) } \\
\hline Fvalues & $14.22^{*}$ & 5.47 & $14.03^{*}$ & $24.33^{*}$ & 11.0 \\
\hline \multicolumn{6}{|l|}{ Maximum heart rate (beats/min) } \\
\hline \multicolumn{6}{|l|}{ Systolic blood pressure (mmHg) } \\
\hline $\begin{array}{l}\text { Fvalues } \\
\text { Diastolic blood pressure }(\mathrm{mmHg})\end{array}$ & 3.22 & 6.31 & 4.87 & $42.82^{*}$ & $25.18^{*}$ \\
\hline $\begin{array}{l}\text { Fvalues } \\
\text { Flexibility }(\mathrm{cm})\end{array}$ & 1.63 & $73.96^{*}$ & 2.59 & 4.93 & $72.0^{*}$ \\
\hline $\begin{array}{l}\text { Flexibility }(\mathrm{cm}) \\
\text { Fvalues }\end{array}$ & 0.20 & 3.57 & 4.47 & $35.27^{*}$ & 1.0 \\
\hline \multicolumn{6}{|l|}{ Agility (s) } \\
\hline \multicolumn{2}{|l|}{ Leg strength (m) } & 4.0 & 3.33 & 1.4 & 5.0 \\
\hline Cardiovascular endurancet $(\mathrm{m})$ & $14.75^{*}$ & $60.19^{*}$ & $66.61^{*}$ & $59.21^{*}$ & $24.95^{*}$ \\
\hline $\begin{array}{l}\text { Physical fitness index } \\
\text { Fvalues } \\
\text { Performance time (min) }\end{array}$ & 4.38 & 3.04 & $11.54^{*}$ & 6.56 & $53.21^{*}$ \\
\hline$F$ values & $59.0^{*}$ & $159.0^{*}$ & $284.67^{*}$ & $140.17^{*}$ & $44.5^{*}$ \\
\hline
\end{tabular}

$* P<0.01$; two-way analysis of variance $(\alpha=0.01) ;+9$-min run for boys under 12 years and 12 -min run for boys over 12 years; $n$, sample size

Table 4. Differences in the control group before and after 12 weeks on selected physical and physiological variables

\begin{tabular}{|c|c|c|c|c|c|}
\hline \multirow[b]{2}{*}{ Variable } & \multicolumn{5}{|c|}{ Age group } \\
\hline & $\begin{array}{c}10 \text { years } \\
C G, n=5\end{array}$ & $\begin{array}{c}11 \text { years } \\
C G, n=5\end{array}$ & $\begin{array}{c}12 \text { years } \\
C G, n=5\end{array}$ & $\begin{array}{c}13 \text { years } \\
C G, n=5\end{array}$ & $\begin{array}{c}14 \text { years } \\
C G, n=5\end{array}$ \\
\hline \multicolumn{6}{|l|}{ Height (m) } \\
\hline$F$ values & 0 & 0 & 0 & 0 & 0 \\
\hline \multicolumn{6}{|l|}{ Weight (kg) } \\
\hline$F$ values & 7.33 & 0.04 & 10.33 & 12.2 & 3.14 \\
\hline \multicolumn{6}{|l|}{ Resting heart rate (beats/min) } \\
\hline Fvalues & 2.67 & 4.57 & 12.25 & $32.67^{*}$ & $32.68^{*}$ \\
\hline \multicolumn{6}{|l|}{ Maximum heart rate (beats/min) } \\
\hline$F$ values & 3.5 & 1.0 & $36.0^{*}$ & $36.0^{*}$ & $42.67^{*}$ \\
\hline \multicolumn{6}{|l|}{ Systolic blood pressure $(\mathrm{mmHg})$} \\
\hline$F$ values & 4.57 & 10.0 & $32.0^{*}$ & 16.0 & 16.0 \\
\hline \multicolumn{6}{|l|}{ Diastolic blood pressure $(\mathrm{mmHg})$} \\
\hline \multirow{2}{*}{\multicolumn{6}{|c|}{ Flexibility (cm) }} \\
\hline & & & & & \\
\hline$F$ values & 0.28 & 0.18 & 5.67 & 0.28 & 0.28 \\
\hline \multicolumn{6}{|l|}{ Agility (s) } \\
\hline Fvalues & 1.33 & 2.5 & 10.0 & 0.36 & 4.44 \\
\hline \multicolumn{6}{|l|}{ Speed $(\mathbf{s})$} \\
\hline Fvalues & 2.0 & 2.0 & 8.67 & 1.33 & 12.0 \\
\hline \multicolumn{6}{|l|}{ Leg strength (m) } \\
\hline Fvalues & 0 & 0 & 0 & 0 & 0 \\
\hline \multicolumn{6}{|l|}{ Cardiovascular endurancet $(m)$} \\
\hline$F$ values & 8.83 & 13.44 & 17.99 & 21.12 & 9.78 \\
\hline \multicolumn{6}{|l|}{ Physical fitness index } \\
\hline$F$ values & 1.79 & 2.37 & 11.79 & $29.78^{*}$ & 18.51 \\
\hline \multicolumn{6}{|l|}{ Performance time (min) } \\
\hline$F$ values & 3.0 & 5.0 & 1.0 & 3.33 & 0.83 \\
\hline
\end{tabular}


improvement is much higher in the experimental group when it is compared with the control group (Table 5). Maximum heart rate was found to be significantly reduced after training in all of the experimental group (Table 3) and in 12-14-year-old boys in the control group (Table 4). Wilmore ${ }^{9}$ suggested that endurance training produces a significant change in normal heart rate in sedentary individuals and it is reduced by about 1 beat $/ \mathrm{min}$ for each week of the training programme. Our findings agree with the findings of Wilmore 9 . Maximum heart rate reductions are found in most studies where the initial values are 180 beats/min. In our studies maximum heart rate is also significantly reduced in all age groups by this training programme, so our findings are comparable with the findings in other studies.

\section{Systolic and diastolic blood pressure}

Resting blood pressure shows mixed results with little or no change being reported in most investigations. Boyer and Kasch ${ }^{10}$ found significant reductions in both systolic and diastolic blood pressure in hypertensive patients after 6 months of training. Both resting systolic and diastolic pressure differ little between sedentary and trained normal subjects. In our studies we found a significant reduction in systolic blood pressure in 13- and 14-year-old boys in the experimental group (Table 3). Except for 12-yearold boys, the control group did not show any significant reductions in systolic and diastolic blood pressure (Table 4). Only 11- and 14-year-old boys in the experimental group showed significant reductions in diastolic pressure after training (Table 3), but

Table 5. The percentage improvement of performance of the experimental and control groups in different tests after 12 weeks of the training programme

\begin{tabular}{|c|c|c|c|c|c|}
\hline \multirow[b]{2}{*}{ Variable } & \multicolumn{5}{|c|}{$\%$ Improvement of performance by age group (category) } \\
\hline & $\begin{array}{c}10 \text { years } \\
E G, n=9 \\
C G, n=5\end{array}$ & $\begin{array}{c}11 \text { years } \\
E G, n=9 \\
C G, n=5\end{array}$ & $\begin{array}{c}12 \text { years } \\
E G, n=9 \\
C G, n=5\end{array}$ & $\begin{array}{c}13 \text { years } \\
E G, n=8 \\
C G, n=5\end{array}$ & $\begin{array}{c}14 \text { years } \\
E G, n=6 \\
C G, n=5\end{array}$ \\
\hline \multicolumn{6}{|c|}{ Height (m) } \\
\hline EG & 1 & 1 & 1 & 1 & 1 \\
\hline CG & 1 & 1 & 1 & 0 & 0 \\
\hline \multicolumn{6}{|c|}{ Weight (kg) } \\
\hline EG & 4 & 8 & 7 & 3 & 4 \\
\hline CG & 1 & 0 & 2 & 2 & 1 \\
\hline \multicolumn{6}{|c|}{ Resting heart rate (beats/min) } \\
\hline EG & 13 & 17 & 14 & 23 & 20 \\
\hline CG & 1 & 2 & 3 & 4 & 4 \\
\hline \multicolumn{6}{|c|}{ Maximum heart rate (beats/min) } \\
\hline EG & 6 & 7 & 6 & 8 & 5 \\
\hline CG & 1 & 0 & 1 & 1 & 1 \\
\hline \multicolumn{6}{|c|}{ Systolic blood pressure $(\mathrm{mmHg})$} \\
\hline EG & 5 & 9 & 9 & 10 & 22 \\
\hline CG & 3 & 2 & 3 & 2 & 1 \\
\hline \multicolumn{6}{|c|}{ Diastolic blood pressure $(\mathrm{mmHg})$} \\
\hline EG & 6 & 2 & 7 & 5 & 18 \\
\hline CG & $\mathbf{0}$ & $\overline{0}$ & 2 & 2 & 1 \\
\hline \multicolumn{6}{|c|}{ Flexibility $(\mathrm{cm})$} \\
\hline EG & 1 & 3 & 6 & 1 & 0 \\
\hline CG & 0 & 0 & 2 & 0 & 0 \\
\hline \multicolumn{6}{|l|}{ Agility (s) } \\
\hline EG & 19 & 12 & 5 & 2 & 3 \\
\hline CG & 1 & 2 & 1 & 0 & 3 \\
\hline \multicolumn{6}{|l|}{ Speed (s) } \\
\hline EG & 7 & 11 & 9 & 6 & 12 \\
\hline CG & 0 & 2 & 3 & 1 & 1 \\
\hline \multicolumn{6}{|c|}{ Leg strength $(m)$} \\
\hline EG & 9 & 5 & 3 & 0 & 3 \\
\hline CG & 0 & 1 & 1 & 0 & 1 \\
\hline \multicolumn{6}{|c|}{ Cardiovascular endurance ${ }^{*}(\mathrm{~m})$} \\
\hline EG & 15 & 24 & 26 & 16 & 17 \\
\hline CG & 0 & 5 & 5 & 6 & 3 \\
\hline \multicolumn{6}{|c|}{ Physical fitness index } \\
\hline EG & 15 & 12 & 18 & 25 & 18 \\
\hline CG & 1 & 2 & 2 & 3 & 2 \\
\hline \multicolumn{6}{|c|}{ Performance time (min) } \\
\hline EG & 5 & 8 & 22 & 24 & 23 \\
\hline CG & 1 & 1 & 0 & 2 & 1 \\
\hline
\end{tabular}

EG, experimental group; CG, control group; $n$, sample size; *9-min run for boys under 12 years and 12 -min run for boys over 12 years 
the percentage of reductions in systolic and diastolic blood pressure is much higher in the experimental group (Table 5).

\section{Flexibility}

This type of training programme did not show any significant change in flexibility among 10-14-year-old boys in the experimental group except for 13-year-old boys (Table 3$)$. The percentage of improvement $(6 \%)$ was highest in 12-year-old boys in the experimental group, though it is not statistically significant. Singh et al.11 also found no significant improvement in flexibility from the ages of 9 to 16 years in Indian boys. So our investigations do agree with the findings of Singh et al. ${ }^{11}$.

\section{Agility}

Several investigators have reported that agility and coordination abilities improve rapidly before puberty after which the improvement slows down considerably $^{12-14}$. In our investigations, 11- and 12-year-old boys in the experimental group showed significant changes (Table 3) after the training programme, whereas 10-, 13- and 14-year-old boys in the experimental group and all those in the control group did not show any significant change after 12 weeks. The percentage improvement was highest $(19 \%)$ in 10 -year-old boys in the experimental group and then it gradually slowed down (Table 5).

\section{Speed}

Significant change in speed was found only in 10- and 12-year-old boys in the experimental group (Table 3), whereas the control group did not show any significant change (Table 4) after 12 weeks. The highest improvement $(12 \%)$ was found in 14-year-old boys in the experimental group (Table 5). There appeared to be no periods of accelerated improvement as reported by Crasselt ${ }^{15}$ and Koinzer ${ }^{16}$.

\section{Strength}

This type of training did not improve muscle strength in the experimental group (Table 3). Many authors have reported a rapid increase in strength performances ${ }^{12,17-19}$ but in our investigations such a pronounced increase in strength was not apparent. This variation may have been due to the cross-sectional studies such as the 12-week training programme. But when this variation was compared with the control group the percentage of improvement was much higher in the experimental group (Table 5).

\section{Cardiovascular endurance and fitness}

The cardiovascular endurance was found to be significantly in all of the experimental group after the training programme (Table 3), whereas the control group did not show any significant change (Table 4). Some authors have reported that continuous training improves cardiovascular endurance ${ }^{18,20}$, and our findings agree with this.
The concept of the percentage of improvement attained in certain physical fitness parameters being related to the initial degree of fitness was proposed in the early work of Müller ${ }^{21}$. In our investigations physical fitness index of 12- and 14-year-old boys in the experimental group (Table 3) and 13-year-old boys in the control group (Table 4) changed significantly after 12 weeks. All other subjects in the experimental and control groups did not show any significant change owing to their initial high level. But the percentage of improvement was much higher in the experimental group when it was compared with the control group (Table 5).

\section{Performance time}

It is already established that training improves performance times. In our investigations these times significantly improved in all of the experimental group (Table 3), whereas those in the control group did not show any significant change (Table 4) after 12 weeks.

From the above investigations we conclude that continuous slow-speed running for 12 weeks in the 10-14-year-old age group, instead of producing any harmful effects, influences the different physiological and motor abilities. As the investigations are crosssectional, it cannot be claimed that this type of training does not produce any detrimental effects on $10-14$-year-old boys in the experimental group. On the other hand, some improvement in physiological and motor abilities in the experimental group indicates that this type of training may be beneficial to them. However, longitudinal prospective studies are required to determine the influence of continuous slow-speed running on the 10-14-year-old age group to establish whether 10-14-year-old boys should be able to take part in long-distance running events or not.

\section{References}

1 Medical Committee of IAAF. Not kids' stuff. Sports Medicine Bulletin 1983; i: 11.

2 American Academy of Pediatrics. Risks in long distance running for children. Physician and Sports Medicine 1982; 10: 82-6.

3 Caine D, Lindner K. Growth plate injury. A threat to young distance runners? Physician and Sports Medicine 1984; 12: 118-24.

4 Lopez R, Pruelt D. The child runner. J Phys Educ Recreation Dance 1982; 53: 78-81.

5 Mayers N, Gutin B. Physiological characteristics of élite pre-pubertal cross-country runners. Med Sci Sports 1979; 11: 172-6.

6 Paty J, Swafford D. Adolescent running injuries. J Adolesc Health Care 1984; 5: 310-13.

7 Rowland T, Walsh C. Characteristics of child distance runners. Physician and Sports Medicine 1985; 137: 45-53.

8 Wilt F. Training for competitive running. In: Falls $\mathrm{H}$, ed. Exercise Physiology. New York, USA: Academic Press, 1968: 395-414.

9 Wilmore JH. Acute and chronic physiological responses to exercise. In: Amsterdam EA, Wilmore JH, DeMaria AN, eds. Exercise in Cardiovascular Health and Diseases. New York, USA: Yorke Medical Books, 1977.

10 Boyer J, Kasch F. Exercise therapy in hypertensive men. JAMA 1970; 211: 1668-71. 
11 Singh H, Joon DS, Kooner K. Development of motor abilities of trained Indian boys of 9-16 years of age. Br J Sports Med 1987; 21: 34-5.

12 Winter R. Die motorische Entwicklung des Menschen von der Geburt bis ins hohe Alter. In: Meinel K, Schnabel G, eds. Bewegungslehre. Berlin, Germany: Volk und Wissen Volkseigenerverlag, 1976: 294-410.

13 Hirtz P. Die Koordinative Vervollkomnung als Wesentliche Bestandteil der Körperlichen Grundausfildung. Körpererziehung 1976; 26.

14 Ludwig G, Hirtz P. Zu Koordinativen-motorischen Vervollkommnung in Klassen 2 bis 4. Körpererziehung 1981; 6: 262-5.

15 Crasselt W. Anthropometrische Werte in Entwicklungsverlauf der Wachstumsperiode. Theorie und Praxis der Körperkultur 1972; 6: 540-55.

16 Koinzer K. Zur Geschlechtsdifferenzierung Konditioneller
Fähigkeiten und ihrer organischen Grundlagen bei untrainierten Kindern und Jugendlichen Schulater. Medizin und Sport 1978; 5: 144-50.

17 Pavek F. Einige Kennziffern der Körperlichen Leistungsfähigkeit 12-19 Jahriger Jugendlichen in der CSSR. Telesne Vychova mladeze Praha 1971; 39: 318-36.

18 Pilicsz S. Die Entwicklung der motorischen Merkmale in Abhängigkeit vom Entwicklungsalter. Kultura Fizyezna Warszawa 1971; 25: 160-1.

19 Komadel L. Sports medizinische Probleme beim Training mit Jugendlichen. Leistungssport 1975; 1: 74-82.

20 Rutenfranz J. Entwicklung der Körperlichen Leistungsfähigkeit im Schul und Jugendalter. Wissenschaftliche Zeitschrift der Humboldt. Universität Berlin. Mathmatische Naturwissenschaftliche Reihe 1965; 14: 335-42.

21 Müller EA. Rev Can Biol 1962; 21: 303-13.

\section{IBULEVE SPORTS GEL PROFESSIONAL TRAINING BURSARY}

Are you a physiotherapist wanting to learn more about sports injury management?

Dendron Ltd - manufacturers of Ibuleve Sports Gel, an anti-inflammatory topical analgesic formulated for use with sports-related muscle injuries - have announced the launch of the Ibuleve Sports Gel Bursary, an award to help physiotherapists develop their knowledge of sport specifc injuries.

The Ibuleve Sports Gel Bursary will enable a suitable delegate to attend the British Association of Sport \& Medicine Intermediate Sports Injury Course - Sports Specific Management and Normal Examination of Joints - at Lilleshall National Sports Centre, November 7-12, 1993.

Applicants should submit a current $\mathrm{CV}$ and no more than 100 words explaining why they warrant this support. The Bursary winner will be asked to prepare a 1,000 word article on their experiences on the course, to be published in the December issue of the British Journal of Sports Medicine.

Applications should be sent to Ibuleve Sports Gel Bursary, c/o Communications Management, Calverton House, 2 Harpenden Road, St Albans, Herts AL3 5AB by Friday 8th October.

For further information, please ring Debbie Bloomfield at Communications Management on 0727850761. 